\title{
Exigências de lisina digestível e de energia metabolizável para codornas de corte em crescimento
}

\author{
Ana Paula Silva Ton ${ }^{1}$, Antonio Claudio Furlan², Elias Nunes Martins ${ }^{2}$, Juliana Beatriz \\ Toledo $^{1}$, Carina Scherer ${ }^{1}$, Ana Carolina Müller Conti ${ }^{1}$
}

1 Programa de Pós-Graduação em Zootecnia da UEM.
2 Departamento de Zootecnia da UEM - 87020-900 - Maringá-PR.

RESUMO - O objetivo neste trabalho foi estimar as exigências de lisina digestível e de energia metabolizável (EM) para codornas de corte (Coturnix coturnix sp) em crescimento. Foram utilizadas 1.680 codornas de 4 a 35 dias de idade, não-sexadas, em delineamento experimental inteiramente casualizado em esquema fatorial $4 \times 4$ ( $\mathrm{LD}=0,92 ; 1,12 ; 1,32$ e $1,52 \% \times \mathrm{EM}=$ 2.800; 2.900; 3.000 e $3.100 \mathrm{kcal} / \mathrm{kg}$ de ração), totalizando 16 dietas, avaliadas com 3 repetições de 35 codornas por unidade experimental. O aumento dos níveis de lisina digestível na ração provocou aumento linear do peso corporal, do ganho de peso, do consumo de lisina e do rendimento de peito e redução do teor de água nos cortes. Quando houve aumento dos níveis de energia metabolizável na ração, observou-se redução linear no consumo de lisina e aumento do peso corporal e do rendimento de gordura abdominal. O aumento simultâneo dos níveis de lisina e energia metabolizável na ração, no entanto, provocou redução linear no consumo de ração e melhora linear da conversão alimentar no período de 4 a 35 dias, mas aumentou o teor de gordura nos cortes. A exigência nutricional de lisina digestível para máximo crescimento de codornas de corte é maior ou igual a 1,52\%. O nível de $2.800 \mathrm{kcal} / \mathrm{kg}$ de EM na ração é suficiente para bom desempenho das aves, contudo, para melhor conversão alimentar, são necessário níveis mais elevados.

Palavras-chave: aminoácidos sintéticos, composição corporal, desempenho

\section{Digestible lysine and metabolizable energy requirements of growing meat quails}

\begin{abstract}
The objective of this experiment was to estimate the digestible lysine and metabolizable energy (ME) requirements for growing meat quails (Coturnix coturnix sp). A total of 1,680 quails from 4 to 35 days of age of both sexes were used in a complete random experimental design in a $4 \times 4$ factorial scheme (DL $=0.92 ; 1.12 ; 1.32$ and $1.52 \% \times \mathrm{ME}=$ 2,800; 2,900; 3,000 and 3,100 kcal/kg of the ration) totaling 16 diets evaluated with 3 replications of 35 quails per experimental diet. Increase of the levels of digestible lysine in the diet linearly increased body weight, weight gain, lysine intake and breast yield and reduced water content in the cuts. When levels of metabolizable energy were increased in the diet, it was observed a linear reduction on consumption of lysine and an increase of body weight and abdominal fat yield. However, The simultaneous increase of levels of lysine and metabolizable energy in the diet linearly reduced feed intake and linearly improved feed conversion in the 4-35 day period, but it increased fat content in the cuts. The nutritional requirement of digestible lysine for maximum growth of meat quails is greater than or equal to $1.52 \%$. The level of $2,800 \mathrm{kcal} / \mathrm{kg} \mathrm{ME}$ in ration is sufficient to allow a good performance of the birds, however, for a better feed conversion, greater levels are needed.
\end{abstract}

Key Words: body composition, performance, synthetic amino acids

\section{Introdução}

A coturnicultura vem se destacando no mercado agropecuário brasileiro como excelente atividade produtiva, por requerer baixos custos com investimento inicial e mão-deobra utilizando pequenas áreas e proporcionando rápido retorno de capital. A maioria das criações édestinada à produção de ovos, porém a demanda pela carne é crescente, tendo em vista sua alta qualidade e palatabilidade (Santos et al., 2005).
Com o crescimento da exploração de codornas de corte, as exigências nutricionais dessas aves têm sido estudadas exaustivamente. O desenvolvimento de planos de nutrição para criação de codornas em condições brasileiras pode contribuir para redução dos custos de produção, pois existe uma preocupação dos nutricionistas em oferecer às aves rações com níveis nutricionais mais adequados, que propiciem melhor desempenho e maior retorno econômico (Silva et al., 2006). 
As fontes proteicas e energéticas das rações têm sido os ingredientes de maior participação nos custos das dietas e que influenciam diretamente a conversão alimentar, a qualidade de carcaça e o ganho de peso das aves (Suida, 2001). São também considerados os componentes de maior importância na prática comercial; devem, portanto, estar em quantidades suficientes para suprir as necessidades das aves, sem onerar seus custos de produção (Forbes \& Shariatmandari, 1994).

O conceito de proteína ideal surgiu como solução e baseia-se no fato de que a exigência de determinado aminoácido essencial como aminoácido digestível passa a ser fornecida à ave desde que as proporções ótimas entre todos os aminoácidos essenciais sejam respeitadas no momento da formulação (Mendoza et al., 2001).

O aminoácido lisina é considerado padrão no conceito de proteína ideal e tem sido usado como referência para atualizar as necessidades de outros aminoácidos, por meio de relações simples (Silva \& Costa, 2009).

A energia não é exatamente um nutriente, mas uma propriedade dos nutrientes em transformar-se em energia quando oxidados durante o metabolismo. Essa energia é liberada como calor ou armazenada para posterior uso nos processos metabólicos dos animais (Murakami \& Furlan, 2002).

Em razão da divergência entre os resultados já publicados sobre as exigências nutricionais de codornas europeias em crescimento, esta pesquisa foi conduzida objetivando-se estimar o melhor nível de lisina digestível e de energia metabolizável para máximo desempenho, rendimento e composição química dos cortes e deposição de proteína e gordura corporal em codornas de corte (Coturnix coturnix sp) em crescimento de 4 a 35 dias de idade.

\section{Material e Métodos}

O experimento foi realizado no Setor de Coturnicultura da Fazenda Experimental de Iguatemi pertencente à Universidade Estadual de Maringá - PR.

Foram utilizadas 1.680 codornas de corte (Coturnix coturnix sp) de 4 a 35 dias de idade, não-sexadas, considerando ao final do experimento a proporção macho:fêmea (número de machos/número de fêmeas) em cada unidade experimental. As aves foram alojadas num galpão convencional, dividido em 48 boxes de $2,5 \mathrm{~m}^{2} \mathrm{e}$ forrados com cama de palha de arroz. O programa de iluminação utilizado foi de 17 horas por dia (natural + artificial) durante todo o período experimental.

As temperaturas, máxima e mínima, foram monitoradas durante todo o período experimental e os valores registrados às $8 \mathrm{~h}$ e às $16 \mathrm{~h}$ da tarde utilizando-se um termômetro de bulbo seco. As temperaturas máxima e mínima médias foram respectivamente, de 28,67 e $16,96^{\circ} \mathrm{C}$ no período da manhã e 29,46 e $18,52^{\circ} \mathrm{C}$ no período da tarde.

O delineamento experimental utilizado foi inteiramente casualizado em esquema fatorial $4 \times 4$ (níveis de lisina digestível $=0,92 ; 1,12 ; 1,32$ e 1,52\% $\times$ níveis de energia metabolizável =2.800; 2.900; 3.000 e 3.100 kcal $/ \mathrm{kg}$ de ração), totalizando 16 dietas com 3 repetições e 35 codornas por unidade experimental.

Depois de alojadas, as codornas receberam as dietas experimentais (Tabela 1) até o final do experimento. As dietas foram à base de milho e farelo de soja, formuladas de acordo com as exigências do NRC (1994), considerando a composição química dos alimentos descrita por Rostagno et al. (2005).

As dietas foram isoproteicas, isocálcicas, isofosfóricas (Tabela 2), com níveis de lisina digestível e energia metabolizável variáveis, assim como os níveis de metionina+cistina, treonina e triptofano digestíveis, de acordo com a relação de aminoácidos proposta por Rostagno et al. (2005) para frangos de corte na fase inicial de 1 a 21 dias de idade, correspondendo à relação de lisina digestível:metionina+cistina, treonina e triptofano digestíveis de 0,$71 ; 0,65$ e 0,16 , respectivamente. Todas as dietas foram suplementadas com aminoácidos sintéticos em quantidades suficientes para se obter a relação de aminoácidos desejada.

As codornas foram pesadas semanalmente e simultaneamente foram realizadas as pesagens das rações experimentais fornecidas, para determinação do peso corporal, do ganho de peso, do consumo de ração, do consumo de lisina, da conversão alimentar e da biomassa corporal acumulada, obtida em relação ao ganho de peso e ao peso inicial das codornas de corte no período de 4 a 35 dias de idade.

Para determinação do rendimento de carcaça, aos 35 dias de idade, foram utilizadas quatro codornas por unidade experimental (12 codornas por tratamento), as quais foram submetidas a 4 horas de jejum e sacrificadas por decapitação entre os ossos occipital e atlas, feito com tesoura, de acordo com as normas propostas pelo Comitê de Ética em Experimentação Animal da Universidade Estadual de Maringá - PR.

As aves foram sangradas por 2 minutos em cone adaptado ao abate de codornas e escaldadas por 20 a 40 segundos a uma temperatura de 53 a $55^{\circ} \mathrm{C}$. A depena foi manual e as aves foram evisceradas por meio de corte abdominal. Para o cálculo de rendimento de carcaça, foi 

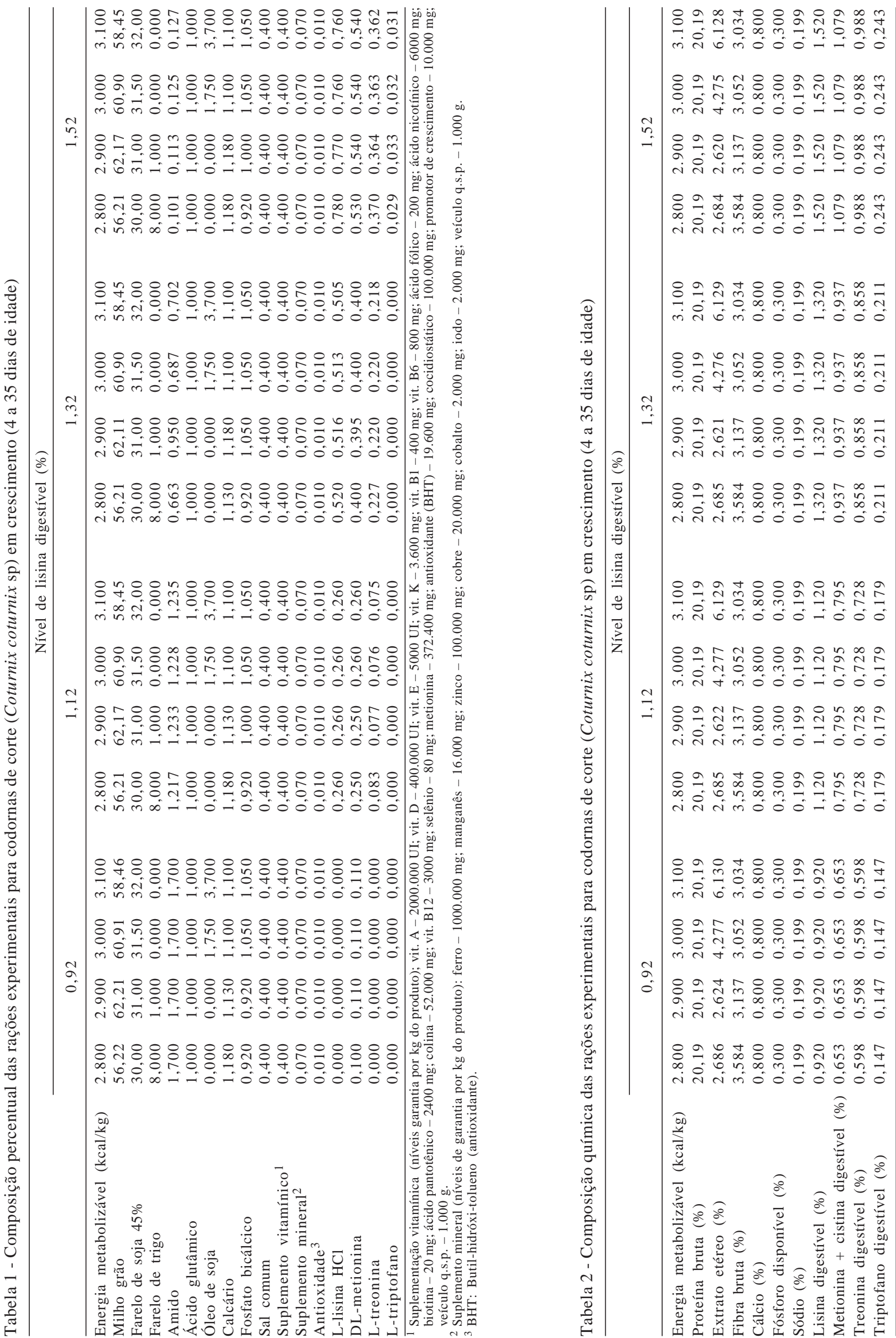
considerado o peso da carcaça eviscerada, sem os pés, cabeça e gordura abdominal, em relação ao peso vivo, o qual foi obtido individualmente antes do abate das aves. Para determinação do rendimento de cortes, foram considerados os rendimentos de peito inteiro, pernas (coxa e sobrecoxa) e dorso com pele e osso, calculados em relação ao peso da carcaça eviscerada.

A gordura abdominal foi constituída pelo tecido adiposo presente ao redor da cloaca, moela, proventrículo e dos músculos abdominais adjacentes, conforme descrito por Smith (1993), e também foi calculada em relação ao peso da carcaça eviscerada.

No estudo da composição química dos cortes (peito, pernas e dorso com pele e osso), foram considerados os cortes obtidos durante o rendimento de carcaça. Os cortes foram congelados em sacos plásticos devidamente identificados por tratamento e repetição e, posteriormente, foram moídos em moinho de carne industrial. Os cortes moídos foram pesados, homogeneizados e levados à estufa de ventilação forçada a $55^{\circ} \mathrm{C}$ por 72 horas, para a realização da pré-secagem. E após a pré-secagem, os mesmos foram moídos em moinho tipo bola e conduzido ao laboratório de nutrição animal para as determinações analíticas.

Foram determinados os teores de matéria seca, água, proteína bruta, extrato etéreo, cinzas e energia bruta dos cortes, conforme metodologia descrita por Silva \& Queiroz (2004).

Foram calculadas as taxas de deposição de proteína e gordura nos cortes, eficiência de deposição de proteína e energia retida nos cortes, conforme metodologias descritas por Fraga et al. (2008).

A taxa de deposição de proteína nos cortes (TDP) foi calculada por meio do abate referência feito a partir de um grupo adicional de 50 codornas com 4 dias de idade, comparadas com aquelas codornas abatidas ao término do período experimental. A taxa de deposição de proteína nos cortes (g) foi calculada segundo a fórmula:

$$
\mathrm{TDP}=\left(\mathrm{QP}_{\mathrm{cf}}-\mathrm{QP}_{\mathrm{ci}}\right) / \mathrm{PE},
$$

em que: $\mathrm{QP}_{\mathrm{cf}}=$ quantidade final, em gramas, de proteína nos cortes; $\mathrm{QP}_{\mathrm{ci}}=$ quantidade inicial de proteína nos cortes; e $\mathrm{PE}=$ período experimental, em dias. A quantidade final de proteína nos cortes foi obtida multiplicando-se o peso da carcaça de determinado ave, ao final do experimento, pela respectiva proteína bruta nos cortes (PBC), enquanto a quantidade inicial foi obtida pelo peso médio dos cortes do grupo de 50 codornas abatidas inicialmente (abate referência) multiplicado pelo seu teor médio de proteína bruta nos cortes.

A taxa de deposição de gordura nos cortes (TDG) foi calculada segundo a equação:

$$
\mathrm{TDG}=\left(\mathrm{QG}_{\mathrm{cf}}-\mathrm{QG}_{\mathrm{ci}}\right) / \mathrm{PE} \text {, }
$$

em que $\mathrm{QG}_{\mathrm{cf}}=$ quantidade, em gramas, de gordura nos cortes final; $\mathrm{QG}_{\mathrm{Ci}}=$ quantidade de gordura nos cortes inicial e PE é o período experimental, em dias. $\mathrm{QG}_{\mathrm{cf}}$ e $\mathrm{QG}_{\mathrm{ci}}$ foram obtidas de modo similar às quantidades inicial e final de proteína nos cortes, utilizando-se os valores de extrato etéreo nos cortes em vez de proteína bruta.

A eficiência de deposição de proteína (EDP) foi calculada pela fórmula:

$$
\mathrm{EDP}=\mathrm{TDP} / \mathrm{CDL} \text {, }
$$

em que TDP = taxa de deposição de proteína, em gramas; e $\mathrm{CDL}=$ consumo diário de lisina, em gramas.

A energia retida nos cortes (ERC) foi calculada utilizando-se a fórmula:

$$
\mathrm{ERC}=5,66 \mathrm{TDP}+9,37 \mathrm{TDG} \text {, }
$$

em que 5,66 e 9,37 os valores energéticos (em kcal/g) da proteína e da gordura, respectivamente, indicados por Sakomura (2004).

A análise estatística dos dados foi realizada por meio do Sistema para Análises Estatísticas - SAEG (UFV, 1993): $\mathrm{Y}_{\mathrm{ijkl}}=\mathrm{b}_{0}+\mathrm{b}_{1} \mathrm{~L}_{\mathrm{i}}+\mathrm{b}_{2} \mathrm{E}_{\mathrm{j}}+\mathrm{b}_{3} \mathrm{~L}_{\mathrm{i}}^{2}+\mathrm{b}_{4} \mathrm{E}_{\mathrm{j}}^{2}+\mathrm{b}_{5} \mathrm{LE}_{\mathrm{ij}}+\mathrm{b}_{6} \mathrm{~S}_{\mathrm{k}}+$ $\mathrm{FA}+\mathrm{e}_{\mathrm{ijkl}}$

em que $\mathrm{Y}_{\mathrm{ijkl}}=$ variável medida na unidade experimental l, da proporção do sexo k, alimentada com dieta contendo o nível i de lisina e o nível j de energia metabolizável; $\mathrm{b}_{0}$ = constante geral; $b_{1}=$ coeficiente de regressão linear em função do nível de lisina digestível; $\mathrm{L}_{\mathrm{i}}=$ nível de lisina digestível; $\mathrm{L}_{1}=0,92 ; \mathrm{L}_{2}=1,12 ; \mathrm{L}_{3}=1,32$ e $\mathrm{L}_{4}=1,52 \% ; \mathrm{E}_{\mathrm{j}}=$ nível de energia metabolizável, $\mathrm{E}_{1}=2.800 ; \mathrm{E}_{2}=2.900 ; \mathrm{E}_{3}=3.000 \mathrm{e}$ $\mathrm{E}_{4}=3.100 \mathrm{kcal} / \mathrm{kg}$ de ração; $\mathrm{b}_{2}=$ coeficiente de regressão linear em função do nível de energia metabolizável; $\mathrm{b}_{3}=$ coeficiente de regressão quadrático em função do nível de lisina digestível; $\mathrm{b}_{4}=$ coeficiente de regressão quadrático em função do nível de energia metabolizável; $b_{5}=$ coeficiente de regressão linear em função da interação entre o nível de lisina digestível e nível de energia metabolizável; $\mathrm{b}_{6}=$ coeficiente de regressão linear em função da proporção de sexo (número de machos/números de fêmeas) na unidade experimental; $S_{k}=$ efeito da proporção de sexo (número de machos/número de fêmeas) na unidade experimental $l$; $F A$ = falta de ajustamento do modelo de regressão; $e_{i j k l}=$ erro aleatório associado a cada observação.

\section{Resultados e Discussão}

Não houve interação $(\mathrm{P}>0,05)$ entre os níveis de lisina digestível (LD) e energia metabolizável (EM) para as variáveis analisadas e isso indica que os níveis de lisina digestível e energia metabolizável atuaram de maneira independente sobre o desempenho das codornas de corte 
(Tabela 3). De acordo com Enke et al. (2005), as exigências nutricionais variam de acordo com a idade das aves, de modo que, nas primeiras semanas de vida, a exigência de proteína e aminoácidos é maior devido ao rápido crescimento das codornas.

O peso corporal das codornas aos 35 dias de idade aumentou linearmente $(\mathrm{P}<0,05)$ com o aumento dos níveis de lisina digestível (Figura 1). De acordo com a equação de regressão ( $\left.P C=230,862+7,34509 L D, R^{2}=0,83\right)$, para cada $1 \%$ de lisina digestível a mais na ração, houve aumento de 7,35 g no peso corporal aos 35 dias de idade. Assim, o aumento no peso corporal está relacionado principalmente à lisina digestível, pois o metabolismo é orientado principalmente para deposição de proteína corporal (Suida, 2001).

De modo semelhante, o ganho de peso das codornas no período de 4 a 35 dias de idade aumentou linearmente $(\mathrm{P}<0,05)$ com o aumento dos níveis de lisina digestível (Figura 1). De acordo com a equação de regressão (GP = $216,798+7,34366 \mathrm{LD}, \mathrm{R}^{2}=0,83$ ), para cada $1 \%$ de lisina digestível a mais na ração, houve aumento de 7,34 g no ganho de peso aos 35 dias de idade. Diferente do observado neste trabalho, Fridrich et al. (2005) estimaram níveis inferiores de lisina digestível em 1,25 e 1,31\% para máximo peso corporal e ganho de peso com codornas de corte europeias no período de crescimento.

Segundo Corrêa et al. (2007), o ganho de peso de codornas de corte no período de 1 a 42 dias de idade sofreu efeito quadrático dos níveis de lisina da ração e sugeriram o nível 1,65\% de lisina total para maior ganho de peso. Freitas et al. (2006), no entanto, verificaram aumento linear $(\mathrm{P}<0,05)$ no ganho de peso com o acréscimo no nível de energia metabolizável (2.565 a $3.015 \mathrm{kcal} \mathrm{EM/kg)} \mathrm{para}$ codornas de corte no período de 1 a 42 dias de idade.

O aumento do peso corporal e do ganho de peso no período de 4 a 35 dias de idade com o aumento dos níveis de lisina digestível na ração está relacionado ao acelerado desenvolvimento muscular e esquelético das codornas nesse período. A lisina digestível pode ser considerada mais importante que a energia metabolizável na determinação do desempenho das codornas de corte em crescimento, visto que não houve efeito dos teores de energia metabolizável na ração para produzir o melhor desempenho. De acordo com Gonzáles \& Sartori (2002), a taxa relativa de síntese proteica é maior no animal jovem em crescimento, enquanto a taxa relativa de deposição de gordura é maior no animal mais velho.

O consumo de ração reduziu linearmente $(\mathrm{P}<0,05)$ com o aumento dos níveis de lisina e energia metabolizável na ração (Figura 2). De acordo com a equação de regressão $\left(C R=1042,29-37,3727 \mathrm{LD}-0,135813 \mathrm{EM}, \mathrm{R}^{2}=0,96\right)$, o consumo de ração pelas codornas foi ajustado de acordo com os níveis de lisina e energia metabolizável, ou seja, aquelas codornas que consumiram a ração de menor conteúdo aminoacídico e energético compensaram esse baixo suprimento de aminoácido com maior quantidade de alimento como forma de estabelecer o mecanismo regulador do consumo. Esses resultados confirmam os obtidos por Freitas et al. (2006), que observaram redução no consumo de ração com o aumento dos níveis de energia para codornas de corte no período de 1 a 42 dias de idade.

O consumo de lisina aumentou de forma linear $(\mathrm{P}<0,05)$ com o aumento dos níveis de lisina digestível e reduziu, também de forma linear, com o aumento dos níveis de EM na ração $(C L=5,78198+5,50342 L D-0,0017773 E M$, $\mathrm{R}^{2}=0,98$ ) (Figura 2).

Os resultados obtidos para o ganho de peso corroboram os obtidos para peso corporal e, associados ao consumo de lisina, comprovam crescimento muscular máximo com o maior consumo de lisina digestível, indicando que a exigência elevada de lisina digestível para codornas de corte até os 35 dias de idade está relacionada à máxima deposição de proteína muscular.

A conversão alimentar melhorou linearmente $(\mathrm{P}<0,05)$ com o aumento dos níveis de lisina digestível e energia metabolizável na ração no período de 4 a 35 dias

Tabela 3 - Desempenho de codornas de corte de 4 a 35 dias de idade alimentadas com dietas formuladas com diferentes níveis de lisina digestível e energia metabolizável, com base no conceito de proteína ideal

\begin{tabular}{|c|c|c|c|c|c|c|c|c|c|c|}
\hline \multirow[t]{2}{*}{ Variável } & \multicolumn{4}{|c|}{ Lisina digestível (\%) } & \multicolumn{4}{|c|}{ Energia metabolizável (kcal/kg) } & \multirow[t]{2}{*}{$\mathrm{CV}$} & \multirow[t]{2}{*}{ Efeito $^{1}$} \\
\hline & 0,92 & 1,12 & 1,32 & 1,52 & 2.800 & 2.900 & 3.000 & 3.100 & & \\
\hline Peso corporal (g) & 236,79 & 240,25 & 240,69 & 241,56 & 239,17 & 240,34 & 239,79 & 239,99 & 1,811 & Linear $^{2}$ \\
\hline Ganho de peso (g) & 222,70 & 226,12 & 226,82 & 227,39 & 225,11 & 226,39 & 225,55 & 225,98 & 1,941 & Linear $^{2}$ \\
\hline Consumo de ração (g/ave) & 610,02 & 593,07 & 597,84 & 583,27 & 620,36 & 597,86 & 588,64 & 577,33 & 3,642 & Linear 2,3 \\
\hline Consumo de lisina (g/ave) & 5,62 & 6,64 & 7,89 & 8,86 & 7,56 & 7,30 & 7,14 & 7,01 & 3,849 & Linear $^{2,3}$ \\
\hline Conversão alimentar (g/g) & 2,74 & 2,62 & 2,64 & 2,57 & 2,76 & 2,64 & 2,61 & 2,56 & 3,628 & Linear $^{2,3}$ \\
\hline Biomassa corporal acumulada (\%) & 1582,29 & 1601,14 & 1635,70 & 1606,22 & 1602,61 & 1624,70 & 1584,17 & 1613,87 & 3,672 & NS \\
\hline
\end{tabular}

Equação de regressão: Peso corporal = 230,862 + 7,34509LD $\left(\mathrm{R}^{2}=0,83\right)$; Ganho de peso = 216,798 + 7,34366LD $\left(\mathrm{R}^{2}=0,83\right) ;$ Consumo de ração = 1042,29 - 37,3727LD $-0,135813 \mathrm{EM}\left(\mathrm{R}^{2}=0,96\right)$; Consumo de lisina $=5,78198+5,50342 \mathrm{LD}-0,0017773 \mathrm{EM}\left(\mathrm{R}^{2}=0,98\right)$.

$\mathrm{CV}=$ coeficiente de variação; NS = não-significativo; ${ }^{1}$ Análise de regressão; ${ }^{2}$ Efeito linear da lisina digestível; ${ }^{3}$ Efeito linear da energia metabolizável. 




(b)

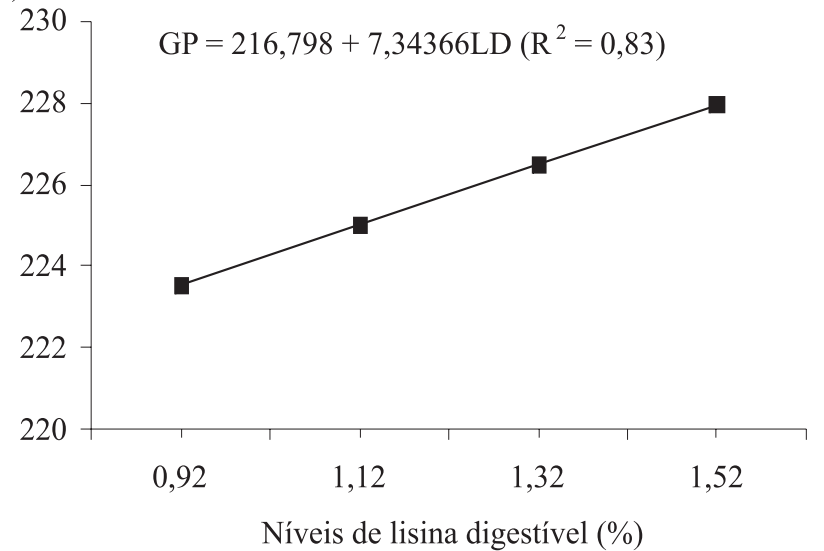

Figura 1 - Peso corporal (a) e ganho de peso (b) de codornas de corte de 4 aos 35 dias de idade de acordo com os níveis de lisina digestível.

$\left(C A=4,76817-0,251201 \mathrm{LD}+0,000617245 E M, \mathrm{R}^{2}=0,93\right)$ (Figura 3), e isso indica que a exigência de lisina digestível e energia metabolizável para melhor conversão alimentar deve ser superior ou igual aos maiores níveis avaliados.

Diferentes resultados foram apresentados por Barreto et al. (2006), em pesquisa com codornas de corte de 21 a 42 dias de idade, e por Moura et al. (2007), com codornas japonesas na fase de 1 a 42 dias de idade. Esses autores não observaram efeito dos níveis de lisina estudados sobre a conversão alimentar.

A biomassa corporal acumulada não foi influenciada ( $\mathrm{P}>0,05)$ pelos níveis de lisina digestível e energia metabolizável no período de 4 a 35 dias de idade. Não houve interação $(\mathrm{P}>0,05)$ entre os níveis de lisina digestível e energia metabolizável sobre as variáveis analisadas, e isso indica que atuaram de maneira independente sobre o rendimento de carcaça das codornas de corte (Tabela 4).

O peso vivo, o peso de peito e o peso e rendimento de carcaça, perna e dorso não foram afetados $(\mathrm{P}>0,05)$ pelos níveis de lisina digestível e energia metabolizável na ração. Esses resultados são semelhantes aos obtidos por Corrêa et al. (2005), que não notaram efeitos dos níveis de proteína bruta (22 a 28\%) e energia metabolizável (2.900 e (a) $\mathrm{CR}=1042,29-37,3727 \mathrm{LD}-0,135813 \mathrm{EM}\left(\mathrm{R}^{2}=0,96\right)$

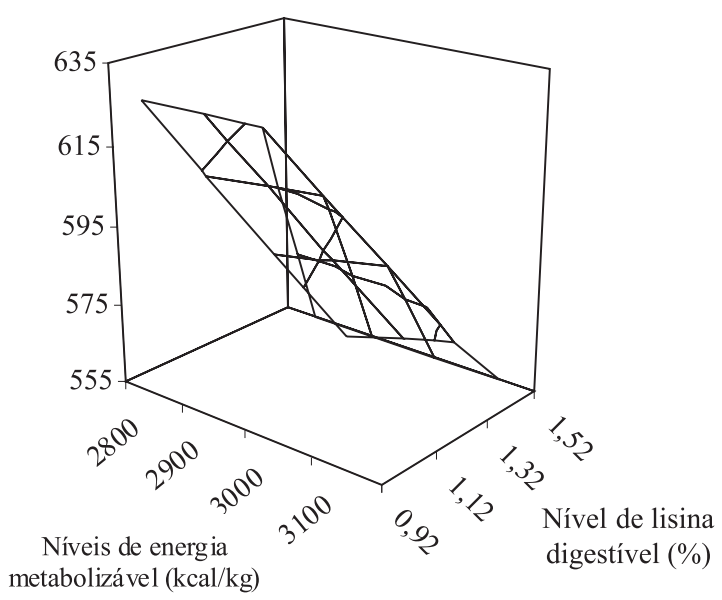

(b) $\mathrm{CL}=5,78198+5,50342 \mathrm{LD}-0,0017773 \mathrm{EM}\left(\mathrm{R}^{2}=0,98\right)$

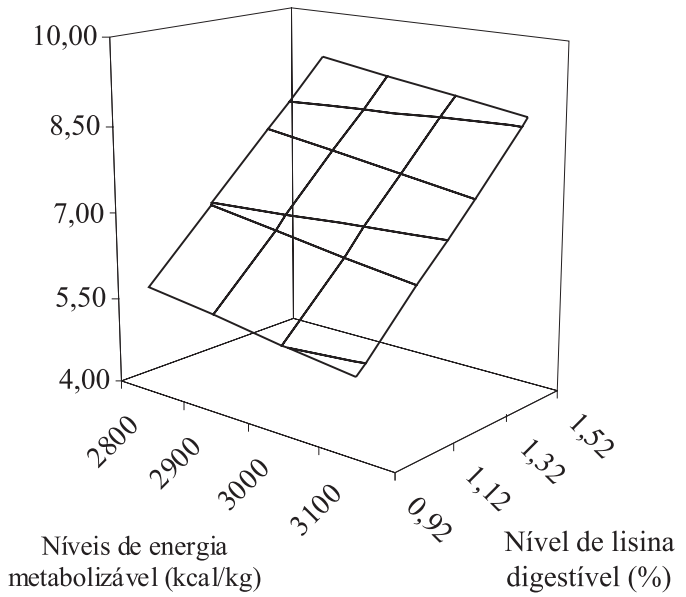

Figura 2 - Consumo de ração (CR) e consumo de lisina (CL) de codornas de corte de 4 a 35 dias de idade em função dos níveis de lisina digestível e energia metabolizável.



Figura 3 - Conversão alimentar de codornas de corte de 4 a 35 dias idade alimentadas com rações formuladas com diferentes níveis de lisina digestível e energia metabolizável. 
Tabela 4 - Rendimento médio de carcaça e de cortes das codornas de corte aos 35 dias de idade alimentadas com dietas com diferentes níveis de lisina digestível e energia metabolizável

\begin{tabular}{|c|c|c|c|c|c|c|c|c|c|c|}
\hline \multirow[t]{2}{*}{ Variável } & \multicolumn{4}{|c|}{ Nível de Lisina digestível (\%) } & \multicolumn{4}{|c|}{ Nível de energia metabolizável (kcal/kg) } & \multirow[t]{2}{*}{$\mathrm{CV}$} & \multirow[t]{2}{*}{ Efeito $^{1}$} \\
\hline & 0,92 & 1,12 & 1,32 & 1,52 & 2.800 & 2.900 & 3.000 & 3.100 & & \\
\hline Peso vivo (g) & 242,50 & 245,04 & 245,69 & 247,65 & 247,90 & 240,94 & 243,46 & 248,58 & 4,452 & NS \\
\hline Rendimento carcaça (\%) & 69,08 & 68,70 & 68,80 & 68,81 & 68,56 & 69,00 & 68,88 & 68,95 & 2,366 & NS \\
\hline Peso do peito (g) & 74,39 & 75,79 & 76,22 & 77,39 & 76,35 & 74,38 & 75,93 & 77,13 & 5,012 & NS \\
\hline Rendimento peito (\%) & 44,39 & 45,04 & 45,12 & 45,44 & 44,95 & 44,75 & 45,28 & 45,00 & 1,781 & Linear $^{2}$ \\
\hline Peso do dorso (g) & 38,96 & 38,77 & 39,26 & 38,37 & 39,08 & 37,69 & 38,45 & 40,15 & 7,140 & NS \\
\hline Rendimento dorso (\%) & 23,29 & 23,02 & 23,23 & 22,52 & 22,99 & 22,68 & 22,95 & 23,44 & 3,971 & NS \\
\hline Peso da gordura abdominal (g) & 1,63 & 1,98 & 1,80 & 2,00 & 1,34 & 1,84 & 1,97 & 2,25 & 30,057 & Linear $^{3}$ \\
\hline $\begin{array}{l}\text { Rendimento da gordura } \\
\text { abdominal (\%) }\end{array}$ & 0,97 & 1,17 & 1,06 & 1,16 & 0,80 & 1,11 & 1,17 & 1,30 & 28,049 & Linear $^{3}$ \\
\hline
\end{tabular}

CV = coeficiente de variação; ${ }^{1}$ Análise de regressão; ${ }^{2}$ Efeito linear da lisina digestível; ${ }^{3}$ Efeito linear da EM; NS = não-significativo.

$3.100 \mathrm{kcal} \mathrm{EM} / \mathrm{kg}$ ) sobre o rendimento de carcaça de codornas europeias aos 42 dias de idade.

$\mathrm{O}$ rendimento de peito (RP) aumentou linearmente $(\mathrm{P}<0,05)$ conforme os níveis de lisina digestível na ração $\left(\mathrm{RP}=44,1874+0,323375 \mathrm{LD}, \mathrm{R}^{2}=0,90\right)$, porém não foi verificado efeito dos níveis de energia metabolizável. Esse resultado pode ser justificado pelo fato de que a lisina digestível é orientada principalmente para deposição de proteína corporal e o peito é o local de maior deposição de tecido muscular (Suida, 2001).

Resultados diferentes foram encontrados por Corrêa et al. (2005) para as características de carcaça, os quais não observaram efeito em codornas de corte aos 42 dias em função do aumento dos níveis de proteína e energia na dieta.

$\mathrm{O}$ peso da gordura abdominal e o seu rendimento aumentaram linearmente $(\mathrm{P}<0,05)$ com o aumento dos níveis de EM na ração, porém não foi verificado efeito $(\mathrm{P}>0,05)$ dos níveis de lisina digestível. $\mathrm{O}$ aumento da gordura abdominal está associado com o excesso de EM na ração e com a alta relação energia:proteína $(147,62)$ utilizada, o que faz com que este excesso de energia seja armazenado pelas codornas na forma de gordura.

Segundo Waldroup (1996), quanto maior a relação energia:proteína, maior a quantidade de gordura abdominal depositada. A quantidade de gordura depositada é diretamente proporcional à quantidade de energia disponível para síntese, portanto, a energia alimentar em excesso é bem correlacionada com a deposição de lipídios na maioria dos animais (Mendonça et al., 2007).

O controle da ingestão de energia é importante não somente por seu efeito na taxa de crescimento, mas também pelos efeitos negativos da ingestão em excesso, que deprecia a qualidade da carcaça pelo maior acúmulo de gordura (Lesson et al., 1996).
O teor de umidade dos cortes (TAC) reduziu linearmente $(\mathrm{P}<0,05)$ com o aumento dos níveis de lisina digestível (TAC = 70,2577-2,61896LD, $\mathrm{R}^{2}=0,96$ ) (Tabela 5), porém não foi observado efeito em função dos níveis de EM. Resultados diferentes foram encontrados por Trindade Neto et al. (2009), que não observaram efeito sobre a umidade na carcaça de frangos de corte aos 49 dias de idade em função dos níveis de lisina digestível.

Foi observada interação significativa $(\mathrm{P}>0,05)$ para 0 teor de proteína na carcaça (TPC) e os níveis de lisina digestível e energia metabolizável (TPC $=-7,79880+$ 25,6951LD+0,00902115EM-0,00888489LD*EM, $\mathrm{R}^{2}=0,65$ ). Nagbi Nascimento et al. (2009), verificaram efeito quadrático da lisina digestível (1,092\%) para máxima deposição de proteína corporal de frangos aos 28 dias de idade.

O teor de gordura e a taxa de deposição de gordura aumentaram linearmente $(\mathrm{P}<0,05)$ com o aumento dos níveis de energia metabolizável, porém não foram observadas diferenças com os níveis de lisina digestível, e isso indica que, acima de $2.800 \mathrm{kcal}$ de EM/kg, havia EM acima das necessidades para deposição proteica, o que levou a deposição de gordura.

Os níveis de EM das rações influenciaram de forma quadrática $(\mathrm{P}<0,05)$ o teor de cinzas nos cortes (TCC) (Figura 4). A estimativa para menor TCC, de 2,68\%, obtido com rações contendo $3.011 \mathrm{kcal} / \mathrm{kg} \mathrm{EM}$, indica que o crescimento do tecido ósseo em relação à massa corporal sofreu redução em função do aumento dos níveis de EM na ração, haja vista que o peso corporal não apresentou efeito deste fator. A presença de altos níveis de energia nas dietas interfere no metabolismo mineral, reduzindo a retenção de cálcio, o teor de cinzas ósseas e o cálcio nos ossos. A formação de sabões insolúveis durante a digestão torna os ácidos graxos indisponíveis para o metabolismo, afetando 
Tabela 5 - Composição química nos cortes de codornas de corte aos 35 dias de idade alimentadas com dietas formuladas com diferentes níveis de lisina digestível e energia metabolizável, com base no conceito de proteína ideal

\begin{tabular}{|c|c|c|c|c|c|c|c|c|c|c|}
\hline \multirow[b]{2}{*}{ Peso de abate (g) } & \multicolumn{4}{|c|}{ Lisina digestível (\%) } & \multicolumn{4}{|c|}{ Energia metabolizável (kcal/kg) } & $\mathrm{CV}$ & Efeito $^{1}$ \\
\hline & 242,50 & 245,04 & 245,69 & 247,65 & 247,90 & 240,94 & 243,46 & 248,58 & 4,452 & NS \\
\hline \multicolumn{11}{|l|}{ Composição química dos cortes } \\
\hline Umidade (\%) & 67,88 & 67,32 & 66,69 & 66,35 & 67,52 & 67,29 & 67,10 & 66,35 & 2,331 & Linear $^{2}$ \\
\hline Proteína (\%) & 18,34 & 18,46 & 17,70 & 18,25 & 18,41 & 18,46 & 17,88 & 17,99 & 3,180 & Interação \\
\hline Gordura (\%) & 11,25 & 11,31 & 12,01 & 12,28 & 11,60 & 11,60 & 12,12 & 12,21 & 12,266 & Linear ${ }^{3}$ \\
\hline \multicolumn{11}{|l|}{ Taxa de deposição } \\
\hline Proteína (g/dia) & 0,87 & 0,89 & 0,85 & 0,89 & 0,89 & 0,88 & 0,86 & 0,88 & 5,037 & NS \\
\hline Gordura (g/dia) & 0,54 & 0,54 & 0,58 & 0,60 & 0,53 & 0,55 & 0,58 & 0,60 & 13,827 & Linear $^{3}$ \\
\hline $\begin{array}{l}\text { Eficiência de deposição de } \\
\text { proteína (g/dia) }\end{array}$ & 0,34 & 0,33 & 0,36 & 0,36 & 0,34 & 0,34 & 0,36 & 0,36 & 14,804 & NS \\
\hline Energia retida nos cortes $(\mathrm{kcal} / \mathrm{g})$ & 9,99 & 10,10 & 10,25 & 10,64 & 9,99 & 10,12 & 10,29 & 10,58 & 8,144 & NS \\
\hline
\end{tabular}

CV = coeficiente de variação; NS = não-significativo.

${ }^{1}$ Análise de regressão; ${ }^{2}$ Efeito linear $(\mathrm{P}<0,05)$ dos níveis de lisina digestível; ${ }^{3}$ Efeito linear $(\mathrm{P}<0,05)$ níveis da energia metabolizável; ${ }^{4}$ Efeito quadrático $(\mathrm{P}<0,05)$ dos níveis de energia metabolizável.

adversamente a taxa de absorção do cálcio (Maioka \& Macari, 2002).

O aumento dos níveis de lisina digestível e energia metabolizável não influenciaram $(\mathrm{P}>0,05)$ a taxa de deposição proteica, a eficiência de deposição proteica e a energia retida nos cortes. De acordo com Lesson (1995), a deposição de proteína é predeterminada pela genética da ave e independente da ingestão ocorre limite de deposição diária que não pode ser compensado. Gonzáles \& Sartori (2002), afirmam que o aumento da proteína corporal ocorre em um período limitado do desenvolvimento. Com o aumento da idade, a deposição de proteína caí mais marcadamente, do que a deposição de gordura.

Segundo Gonzáles \& Sartori (2002), quando existe um estado de equilíbrio do turnover proteico, deve-se esperar que a taxa de síntese seja igual à taxa de degradação. Nesse caso, não há deposição proteica. Existem vários

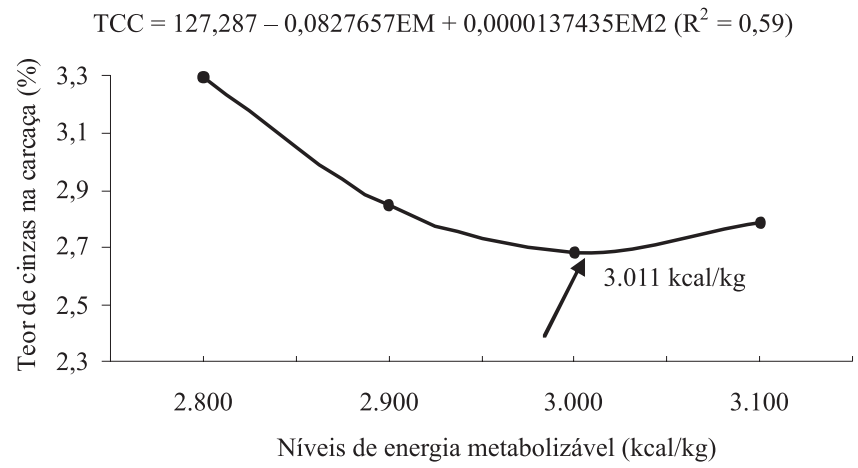

Figura 4 - Teor de cinzas na carcaça de codornas de corte aos 35 dias de idade em função dos níveis de energia metabolizável. fatores que afetam a síntese de proteína e consequentemente o crescimento muscular. Entre eles pode-se citar: nível dietético de aminoácidos (quantidade e balanceamento) e nível energético da ração. A carência ou desbalanceamento entre os nutrientes podem influenciar a síntese ou a degradação proteica de uma maneira indireta, porque podem afetar a liberação de hormônios como GH e insulina, entre outros.

Embora o consumo de lisina tenha apresentado aumento linear em função dos níveis de LD e redução linear em função da energia metabolizável na ração, esse efeito não foi suficiente para influenciar a EDP. Tal efeito também pode ter sido influenciado pela queda no consumo de ração em função dos níveis de LD e EM.

Considerando que a energia retida nos cortes é uma variável dependente das taxas de deposição proteica e de gordura, bem como dos valores energéticos da proteína e gordura (5,66 e 9,37), espera-se que seu comportamento acompanhe o efeito de uma, senão das duas variáveis a que está relacionada, embora a taxa de deposição de gordura tenha apresentado aumento linear $(\mathrm{P}<0,05)$ em função dos níveis de EM, não foi suficiente para promover efeito na variável energia retida nos cortes.

\section{Conclusões}

A exigência nutricional de lisina digestível para máximo crescimento de codornas de corte é maior ou igual a 1,52\%. O nível de $2.800 \mathrm{kcal} / \mathrm{kg}$ de EM na ração é suficiente para proporcionar bom desempenho, contudo, para melhor conversão alimentar, devem ser utilizados níveis mais elevados. 


\section{Agradecimentos}

À Coordenação de Aperfeiçoamento de Pessoal de Nível Superior (CAPES), pelo suporte financeiro. Aos grupos de pesquisa de nutrição de não ruminantes e melhoramento genético animal da Universidade Estadual de Maringá e a todos que colaboraram direta ou indiretamente para a realização deste trabalho.

\section{Referências}

BARRETO, S.L.T.; ARAUJO, M.S.; UMIGI, R.T. et al. Exigência nutricional de lisina para codornas européias machos de 21 a 49 dias de idade. Revista Brasileira de Zootecnia, v.35, n.3, p.750-753, 2006.

CORRÊA, G.S.S.; SILVA, M.A.; FONTES D.O. et al. Efeito de diferentes níveis de proteína e energia sobre o rendimento de carcaça de codornas européias. Arquivo Brasileiro de Medicina Veterinária e Zootecnia, v.57, n.2, p.266-271, 2005.

CORRÊA, G.S.S.; SILVA, M.A.; CORRÊA, A.B. et al. Desempenho de codornas de corte EV1 alimentadas com diferentes níveis de lisina na dieta. Arquivo Brasileiro de Medicina Veterinária e Zootecnia, v.59, n.6, p.1545-1553, 2007.

ENKE, S.D.B.; DUTRA, D.G.; FREITAS, L.C. Aves e ovos. In: SOUZA-SOARES, L.A.; SIEWEDT, F. (Eds.) Criação de codornas. Pelotas: Universidade UFPEL, 2005. p.23-33.

FORBES, J.M.; SHARIATMANDARI, F. Diet selection for protein by poultry. World's Poultry Science Journal, v.50, n.1, p.7-23, 1994.

FRAGA, A.L.; MOREIRA, I.; FURLAN, A.C. et al. Lysine requirement of starting barrows from two genetic groups, fed on low crude protein deits. Brazilian Archives of Biology and Technology, v.51, p.49-56, 2008.

FREITAS, A.C.; FUENTES, M.F.F.; FREITAS, E.R. et al. Níveis de proteína bruta e energia metabolizável na ração para codornas de corte. Revista Brasileira de Zootecnia, v.35, n.4, p.1705-1710, 2006 (supl.).

FRIDRICH, A.B.; VALENTE, B.D.; FELIPE-SILVA, A.S. et al. Exigência de proteína bruta para codornas européias no período de crescimento. Arquivo Brasileiro de Medicina Veterinária e Zootecnia, v.57, n.2, p. 261-265, 2005.

GONZALES, E.; SARTORI, J.R. Crescimento e metabolismo muscular. In: MACARI, M.; FURLAN, R.L.; GONZALES, E. (Eds.) Fisiologia aviária aplicada a frangos de corte. Jaboticabal: FUNEP/UNESP, 2002. 375p.

LEESON, S. Nutrição e qualidade de carcaça de frangos de corte. In: CONFERÊNCIA APINCO DE CIÊNCIA E TECNOLOGIA AVÍCOLA, 1995, Curitiba. Anais... Campinas: FACTA, 1995. p.111-118.

LEESON, S.; CASTON, L.; SUMMERS, J.D. Broiler response to energy diet. Poultry Science, v.75, p.529-535, 1996.

MAIORKA, A.; MACARI, M. Absorção de minerais. In: MACARI, M.; FURLAN, R.L.;GONZALES, E. (Eds.) Fisiologia aviária aplicada a frangos de corte. Jaboticabal: FUNEP/UNESP, 2002. 375p.

MENDONÇA, M.O.; SAKOMURA, N.K.; SANTOS, F.R. et al. Níveis de energia metabolizável e relações energia:proteína para aves de corte de crescimento lento criadas em sistema semiconfinado. Acta Scientiarum.Animal Sciences, v.29, n.1, p.23-30, 2007.

MENDOZA, M.O.B.; COSTA, P.T.C.; KATZER, L.H. et al. Desempenho de frangos de corte, sexados, submetidos a dietas formuladas pelos conceitos de proteína bruta versus proteína ideal. Ciência Rural, v.31, n.1, p.111-115, 2001.

MOURA, A.M.A.; SOARES, R.T.R.N.; FONSECA, J.B. et al. Exigência de lisina para codornas japonesas (Coturnix japonica) na fase de cria. Ciência e Agrotecnologia, Lavras, v.31, n.4, p.1191-1196, 2007.

MURAKAMI, A.E.; FURLAN, A.C. Pesquisas na nutrição e alimentação de codornas em postura no Brasil. In: SIMPÓSIO INTERNACIONAL COTURNICULTURA, 1., 2002, Lavras. Anais... Lavras: Universidade Federal de Lavras/NECTA, [2002]. (CD-ROM).

NAGIB NASCIMENTO, D.C.; SAKOMURA, N.K.; SIQUEIRA, J.C. et al. Exigências de lisina digestível para aves de corte da linhagem ISA Label criadas em semiconfinamento. Arquivo Brasileiro de Medicina Veterinária e Zootecnia, v.61, n.5, p.1128-1138, 2009.

NATIONAL RESEARCH COUNCIL - NRC. Nutrient requirements of poultry. 9.ed. Washington, D.C.: University Press, 1994. $155 p$.

ROSTAGNO, H.S.; ALBINO, L.F.L.; DONZELE, J.L. et al. Tabelas brasileiras para aves e suínos: composição de alimentos e exigências nutricionais. 2.ed. Viçosa, MG: UFV, 2005. 186p.

SAKOMURA, N.K. Modeling energy utilization in broiler breeders, laying hens and broilers. Revista Brasileira de Ciência Avícola, v.6, n.1, p.1-11, 2004.

SANTOS, G.G.; CORRËA, G.S.S.; SILVA, M.A. et al. Avaliação de carcaça de codornas GSS1 para corte alimentadas com dietas contendo diferentes níveis de metionina + cistina. In: REUNIÃO ANUAL DA SOCIEDADE BRASILEIRA DE ZOOTECNIA, 42., 2005, Goiânia. Anais... Goiânia: Sociedade Brasileira de Zootecnia. (CD-ROM).

SILVA, D.J.; QUEIROZ, A.C. Análises de alimentos: métodos químicos e biológicos. 3.ed. Viçosa, MG: UFV, 2004. 235p.

SILVA, E.L.; SILVA, J.H.V.; JORDÃO FILHO, J. et al. Redução dos níveis de proteína e suplementação aminoacídica em rações para codornas européias (Coturnix coturnix coturnix). Revista Brasileira de Zootecnia, v.35, n.3, p.822-829, 2006.

SILVA, J.H.V.; COSTA, F.G.P. Tabela para codornas japonesas e européias. Jaboticabal: Funep, 2009. 107p.

SMITH, M.O. Parts yield of broilers reeared under eyeling hight temperatures. Poultry Science, v.72, p.1146-1150, 1993.

SUIDA, D. Formulação por proteína ideal e conseqüências técnicas, econômicas e ambientais. In: SIMPÓSIO INTERNACIONAL DE NUTRIÇÃO ANIMAL: PROTEÍNA IDEAL, ENERGIA LÍQUidA E MODElageM, 1., 2001, Santa Maria. Anais... Santa Maria: 2001. p.27-43.

TRINDADE NETO, M.A.; TAKEARA, P.; TOLEDO, A.L. et al. Níveis de lisina digestível para frangos de corte machos no período de 37 a 49 dias de idade. Revista Brasileira de Zootecnia, v.38, n.3, p.508-214, 2009.

UNIVERSIDADE FEDERAL DE VIÇOSA - UFV. Sistema de análises estatísticas e genéticas - SAEG. Versão 5.0 . Viçosa, MG: 1997. 150p.

WALDROUP, P.W. Nutrient requirement of broilers. In: SIMPÓSIO INTERNACIONAL SOBRE EXIGÊNCIAS NUTRICIONAIS DE AVES E SUÍNOS, 1996, Viçosa, MG. Anais... Viçosa, MG: Universidade Federal de Viçosa, 1996. p.55-63. 